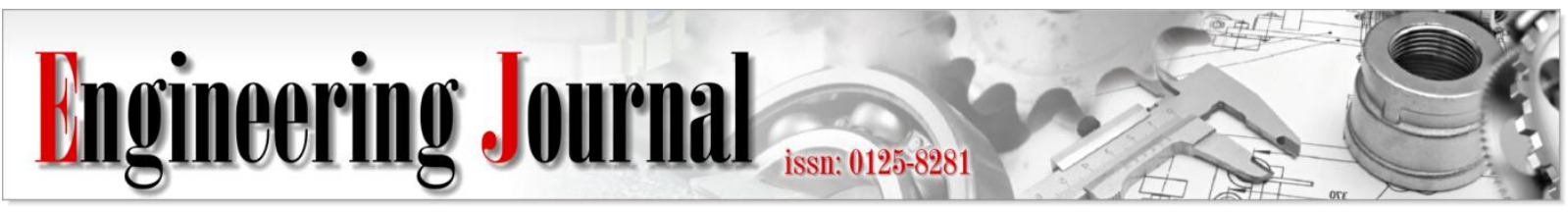

Article

\title{
Flexural Performances of Epoxy Aluminium Particulate Composites
}

\author{
Sefiu Adekunle Bello ${ }^{1,2, a, b, *}$, Johnson Olumuyiwa Agunsoye ${ }^{2}$, Jeleel Adekunle Adebisi ${ }^{3}$, \\ Nasirudeen Kolawole Raji ${ }^{4}$, Raphael Gboyega Adeyemo ${ }^{5}$, Abdul Ganiyu Funsho Alabi ${ }^{1}$, \\ and Suleiman Bolaji Hassan ${ }^{2}$ \\ 1 Department of Materials Science and Engineering, Kwara State University, Malete, Nigeria \\ 2 Department of Metallurgical and Materials Engineering, University of Lagos, Nigeria \\ 3 Department of Metallurgical and Materials Engineering, University of Ilorin, Nigeria \\ 4 Department of Metallurgical Engineering, Yaba College of Technology, Yaba, Nigeria \\ 5 Gateway (ICT) Polytechnic, Saapade, Ogun State, Nigeria \\ E-mail: asefiu.bello@kwasu.edu.ng, badekunleshaafiu@gmail.com (Corresponding author)
}

\begin{abstract}
Polymers are characterised with lightness, ease of formability and resistance to chemical attack but their modulus and strength are low. Epoxy was reinforced with aluminium particles of different sizes. Bond, functional group and chemical formulae of the composite phases were examined using Fourier Transform Infrared Spectroscopy (FTIR) and X-ray diffractometer. The flexural test was also conducted on the developed composites via three-point method. Analysis of variance (ANOVA) was performed using aluminium percentage by weight $(\mathrm{wt} \%)$ and sizes $(\mathrm{Ps})$ as the predictor variables. Results indicated different chemical formulae of the composite phases. A maximum of $124.44 \%$ increase in flexural modulus was found at $12 \mathrm{wt} \%$ reinforcement addition. Probability value, 0.000 for each of $\mathrm{wt}^{0} \%$ and $\mathrm{Ps}$ affirm evenly significant influence of both variables on flexural modulus of the composites. Hence, the developed multiple regression model can be used for predicting the flexural modulus of epoxy particulate composites within and outside the scope of experiment.
\end{abstract}

Keywords: Flexural strength, modulus, regression, ANOVA.

ENGINEERING JOURNAL Volume 22 Issue 4

Received 11 November 2017

Accepted 14 April 2018

Published 31 July 2018

Online at http://www.engj.org/

DOI:10.4186/ej.2018.22.4.97 


\section{Introduction}

Polymer composites are materials containing a polymeric continuous phase and discontinuous phases known as reinforcing fillers [1,2]. Currently, polymeric composites are involving as transportation materials either in automobile or aerospace industries. Their uses for replacing heavy alloy leads to a reduction in individual components of automobiles making light composite automobiles cost effective [3]. In addition, safety; vehicle styling and fuel efficiency are improved $[4,5]$.

Polymers are soft, light and resistant to chemical attack but their low mechanical properties limit their applications in engineering structures [6]. In developing polymeric composites, attempt to improve mechanical properties of polymers; conventional aramid, glass, carbon and natural bamboo, coconut, palm kernel, bagasse fibres have been used [7,8]. Among polymers is epoxy resin which has a good thermal stability, low shrinkage on curing and has been used as a matrix for developing high performance composites for engineering applications [9]. Different grades of fibre reinforced epoxy composites are common in literatures using either conventional or natural fibres but anisotropy in properties and difficulty in manufacturing still exist [10].

Currently, many researches across globe are centred on reinforcing epoxy with aluminium particles to produce particulate reinforced composites which may replace anisotropic fibre reinforced epoxy composites. Many studies have been found on electrical, thermal, wear and mechanical: tensile; micro hardness and compressive properties [11-13]. However, studies of flexural properties of epoxy/aluminium composites are scarce. For possible use of epoxy/aluminium composites for automobile applications, apart from tensile; impact and micro hardness properties, knowledge of flexural performance of the epoxy/aluminium composites are very important especially in automobile bumpers where resistance to bending is a prerequisite to enhance safety in accidental vehicle collision with an obstacle. This study is aimed at studying flexural properties of epoxy/aluminium composites through experiment and regression analyses. Also, the focus is made on comparing flexural properties of epoxy/aluminium micro and nanocomposites to appraise effects of particle size on the flexural properties of the composites.

\section{Materials and Methods}

Epoxy resin (diglycidyl ether of bisphenol A), hardener (benzene -1,3-diethanamine), ethanol and aluminium particles were the materials used in the study. Epoxy resin/hardener (grade MAX 1618A/B with 2/1 mixing ratio) was bought from Polymer Composite Institute, Ontario Canada, through a resin vendor in Lagos, Nigeria. Densities of epoxy resin and hardener are 1.1 and $0.98 \mathrm{gcm}^{-3}$, respectively. Aluminium micro and nanoparticles used were produced from aluminium cans through combined casting and Topdown approaches $[14,15]$. In developing epoxy composites, a weighed amount of aluminium microparticles equivalent to 2 percentage by weight ( $\mathrm{wt} \%$ ) of epoxy resin was added to ethanol in a container and agitated mechanically for 20 minutes to dissolve aluminium particle agglomerates. Then solution was added to a known quantity of epoxy resin in a beaker and stirred manually for five minutes using a glass rod. This was followed by mechanical stirring at 314 revolution per minutes (rpm) for additional 10 minutes. Ethanol was evaporated by heating and stirring the mixture magnetically at $100^{\circ} \mathrm{C}$ for 1 hour using Stuart hotplate/stirrer (model: UC 152). Hardener was added to have 2:1 epoxy resin-hardener volume stoichiometric ratio. The mixture was stirred mechanically for additional 2 minutes, degassing using Shel Lab vacuum oven (model: SVA S2E) and manually stirred again before pouring into an open die steel mould which have been coated with oil for ease of composite removal after curing at room temperature for 48 hours. The composite was post cured at $130{ }^{\circ} \mathrm{C}$ for 4 hours. Percentage weight of aluminium microparticles added to epoxy was increased to $12 \mathrm{wt} \%$ at $2 \mathrm{wt} \%$ interval. The same techniques and $\mathrm{wt}^{0} \%$ of aluminium nanoparticles were used for developing epoxy nanocomposites. Both aluminium nanoparticles and microparticles were analysed using Philip 301 Transmission Electron Microscope (TEM) at Department of Chemical and Metallurgical Engineering, University of Johannesburg (UJ), South Africa and ASPEX 3020 Scanning Electron Microscope with attached energy dispersive X-ray spectroscopy (SEM/EDX) at Department of Materials Science and Engineering, Kwara State University, Malete, Nigeria; respectively. The developed composites were analysed using Shimadzu Fourier Transform Infrared Spectroscopy at Redeemer's University, Ede Osun State, Nigeria; Philip X-ray diffractometer at UJ and SEM. In analysing solid epoxy composite samples using Schimadzu FT-IR, $5 \mathrm{mg}$ of each sample was mixed with $500 \mathrm{~g}$ pure $\mathrm{KBr}$ and compressed inside a stainless-steel container/disc at $17 \mathrm{~N} / \mathrm{mm}^{2}$ in line with $[16,17]$. The sample disc was 
mounted directly on the sample holder and scanned at $4 \mathrm{~cm}^{1}$ resolutions for 45 times to ensure accuracy of the spectra. Epoxy composites were subjected to X-ray diffraction analysis to probe interaction of epoxy with additive fillers through identification of phases present in the epoxy matrix. Samples were prepared using a zero-background sample holder and analysed using Philips X-ray diffractometer with Pixcel detector. The slits were fixed with Fe filtered Co K $\alpha$ radiation at $40 \mathrm{kV}, 30 \mathrm{~mA}$ and $1^{\circ} / 1^{\circ}$ scattering slit and $400 \mu \mathrm{m}$ receiving slit. Intensity/ count scores were recorded between 0 and $90^{\circ}$ diffracting angles $(2 \theta)$ with a scintillation counter at $0.05^{\circ}$ minute. The phases were identified using X' Pert High score plus software; PAB-ICSD and ICDD (2014) databases.

Flexural property test was carried out on the rectangular samples of $120 \mathrm{~mm}$ long (total length), $10 \mathrm{~mm}$ thick and $6 \mathrm{~mm}$ wide using 3-point bending method. The samples were positioned horizontally on two pivots at $60 \mathrm{~mm}$ apart (span length) and loaded perpendicularly at the centre using Instron Universal Tester Machine (model: Instron 3369) until the sample fractured as shown in Fig. 1. Three different samples were tested at each level of reinforcement, equal to a total of 42 samples used in these experiments. Average values of results obtained from the three examined samples at each level of reinforcement were plotted as functions of $\mathrm{wt} \%$ of reinforcements additions and their standard deviations were presented as error bars. The analysis was carried out at room temperature of $18^{\circ} \mathrm{C}$ and $50 \%$ humidity per ASTM D 790-03 [18] with slight modification. The flexural strength, deflection and modulus were estimated using Eq. (1)-(3). F is the applied load; $\mathrm{L}$ is the span length $(60 \mathrm{~mm}), \mathrm{b}$ is the thickness of the sample $(10 \mathrm{~mm})$ and $\mathrm{w}$ is the width $(6 \mathrm{~mm})$. $\mathrm{E}$ is the flexural modulus as used in the equations. To study effects of $\mathrm{wt} \%$ and particle sizes (Ps) of aluminium particles on the flexural modulus of epoxy/aluminium composites, a multiple regression model was developed. Full factorial designs of experiment involving two predictor variables ( $\mathrm{wt}^{\mathrm{0}} \%$ and $\mathrm{Ps}$ ) at 5 different levels (that is $2^{5}=32$ experiments) were used. MATLAB 2009b was used for the multiple regression analysis. Analysis of variance (ANOVA) was performed to ascertain which of the variables has most significant influence on response (flexural modulus). Developed multiple regression model was tested and validated using seven out of remaining ten unused experimental data.

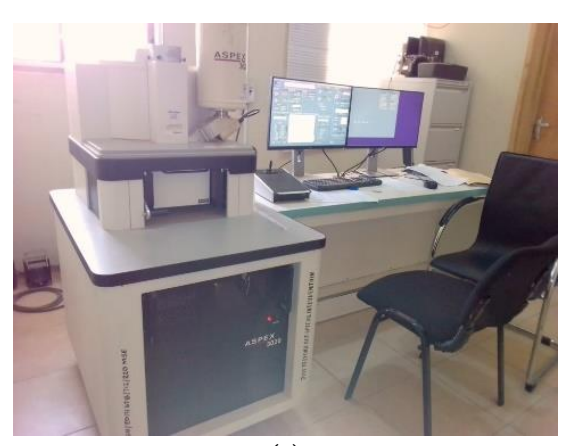

(a)

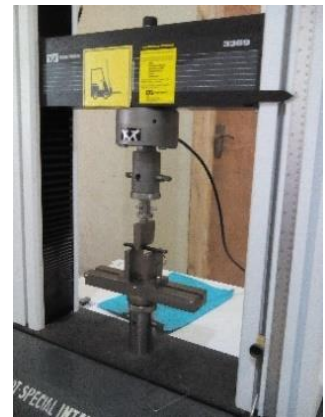

(b)

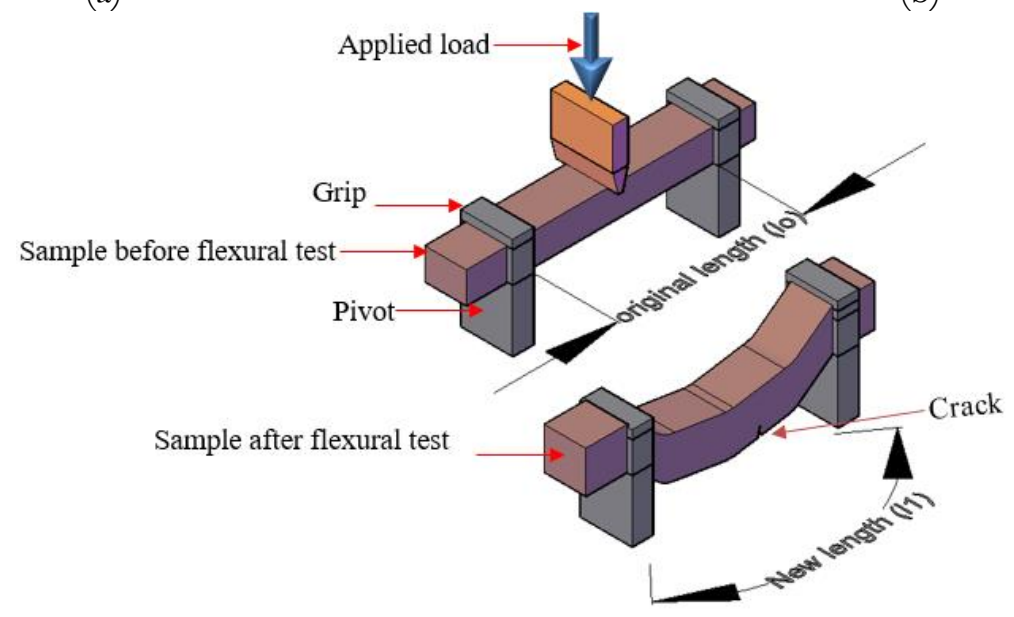

(c)

Fig. 1. Photograph showing (a) ASPEX 3020 for microstructural analysis of the composites; (b) Instron 3369 Universal Testing Machine during flexural test; (c) sample before and after flexural test. 


$$
\begin{gathered}
\sigma_{\text {flex }}=\frac{3 F L}{2 b w^{2}} \\
\varepsilon_{f l e x}=\frac{\text { Flexural extension }(l 1-l o)}{\text { original span length }(l o)} \\
E_{\text {flex }}=\frac{\sigma_{\text {flex }}}{\varepsilon_{\text {flex }}}
\end{gathered}
$$

\section{Results and Discussion}

\subsection{Structure of Epoxy Aluminium Composites}

Figure 2(a) shows the transmittance-wave band of unreinforced epoxy polymer. Each peak is identified with wave band indicating the functional group to which the polymer belongs or bond present in it. The broad peak $\left(3429.55 \mathrm{~cm}^{-1}\right)$ is attributed to $\mathrm{NH}_{2}$ of secondary amine or $\mathrm{OH}$ of secondary alcohol. The sharp peak $\left(2926.11 \mathrm{~cm}^{-2}\right)$ and its shoulder $\left(2854.74 \mathrm{~cm}^{-1}\right)$ are ascribed to aromatic ring which are confirmed by presence of $\mathrm{C}=\mathrm{C}$ aromatic stretching at $1608.69 \mathrm{~cm}^{-1}$ with its shoulder at $1583.61 \mathrm{~cm}^{-1}$ and $\mathrm{C}-\mathrm{C}$ stretching of aromatic at $1510.31 \mathrm{~cm}^{-1}$ in the fingerprint region. $1182.40 \mathrm{~cm}^{-1}$ belongs to $\mathrm{C}-\mathrm{O}$ stretching of aromatic. $1037.74 \mathrm{~cm}^{-1}$ and $827.49 \mathrm{~cm}^{-1}$ reveal C-O-C stretching of ether and C-O-C of oxirane group/aromatic absorbance, respectively. Linking of peaks with functional groups and or bonds are according to [19, 20]. Presence of the bonds and functional group affirm secondary amine and alcohol which are components of the structure developed from additional and cross linking reactions between epoxy resin and the hardener in line with [9]. When the reinforcements were added, changes in wave bands of the peaks were noticed showing differences in stoichiometric balances between the epoxy resin and the hardener as displayed in Figs. 2(b)-(c) revealing chemical properties of epoxy/Almp and epoxy/Alnp composites produced after interaction of epoxy/hardener system with the reinforcements independently. The combined FTIR spectrographs in Fig. 2(d) depict the change in chemical properties of compounds formed when epoxy resin reacted with hardener and those formed when hardener/epoxy system interacted with the reinforcements. Those compounds are fitted with peaks in X-ray diffractometric profiles in Figs. 3(a)-(c). Figure 3(a) shows XRD pattern of unreinforced epoxy polymer. The broad peak between 10 and $30^{\circ}$ was linked to typical amorphous structure of epoxy molecules in line with [21]. Production of semi-crystalline phases due to addition of aluminium microparticles (Almp) and aluminium nanoparticles (Alnp) to epoxy matrix has reduced the amorphous nature of the resulted composites which is justified by observed peaks in Figs. 3(b)-(c), respectively. Particle fineness of Alnp may justify greater number of broader XRD peaks in Fig. 3(c) of epoxy/Alnp composites than that in Fig. 3(b) of epoxy/Almp micro composites since the peak broadness with reduction in grain or particle sizes has been established in literature [22-24]. Moreover, TEM image in Fig. 4(a) shows the structure of Alnp at high resolution. The structure shows a Alnp colony containing many aluminium nanoparticles which has been fused together by the Van der Waal's attraction due to their high surface energy. Their average size is $74.4 \mathrm{~nm}$ according to [14]. Figure 4(b) displays the microstructure of aluminium microparticle (Almp). Their EDX elemental composition in Fig. 4(b) indicates aluminium as major elements. Figure 4(c) shows epoxy molecular structures developed from addition and cross linking reaction between epoxy resin and hardener to form a rigid network of epoxy polymer. This structure is different from what is observed in Figs. 4(d)-(e) due to addition of reinforcing aluminium particles. Semi-crystalline compounds such as $\mathrm{HAlSi}_{289} \mathrm{O}_{580}, \mathrm{C}_{6} \mathrm{H}_{15} \mathrm{~N}-\mathrm{Al}_{2} \mathrm{O}_{3}, \mathrm{SiO}_{2}-\mathrm{P}_{2} \mathrm{O}_{5} \cdot \mathrm{H}_{2} \mathrm{O}$ and $\mathrm{C}_{4} \mathrm{H}_{10} \mathrm{~N}_{2} \mathrm{O}_{5}$ produced from interaction between amorphous epoxy system and crystalline Almp and unreacted Almp are observed sandwiching between epoxy molecules forming a fair homogenous structure. Figure 4(e) shows crest-trough undulating layers containing second phase compounds dispersed within epoxy molecules forming a fine-grained structure of epoxy/Alnp composite. Good adhesion of the second phase compounds with epoxy molecules observed is a sign of good mechanical performance of the developed epoxy/aluminium composites. 

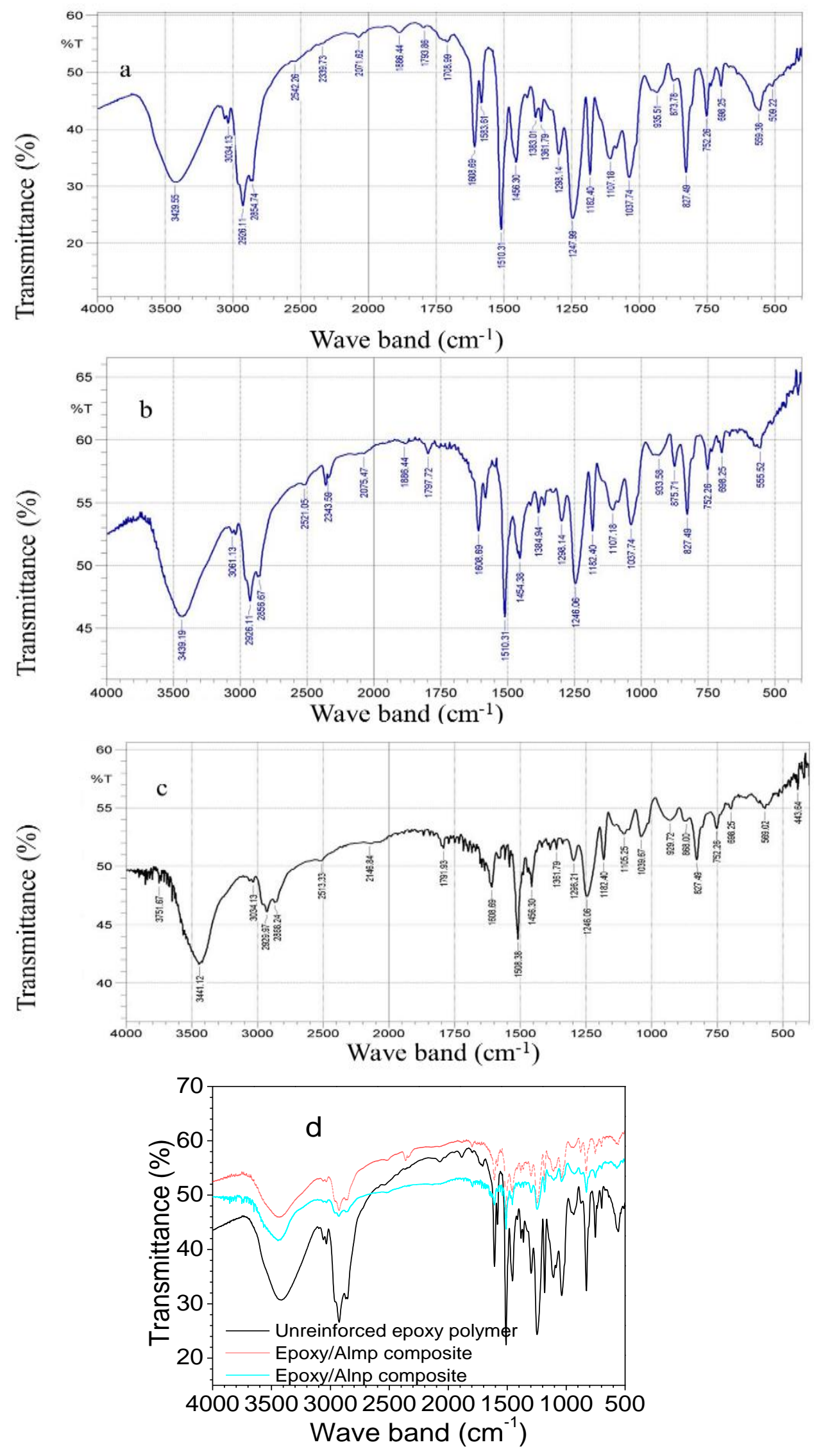

Fig. 2. Bond characteristics of (a) epoxy polymer; (b) epoxy/Almp; (c) epoxy/Alnp composites; (d) superimposed FTIR spectra of all samples. 

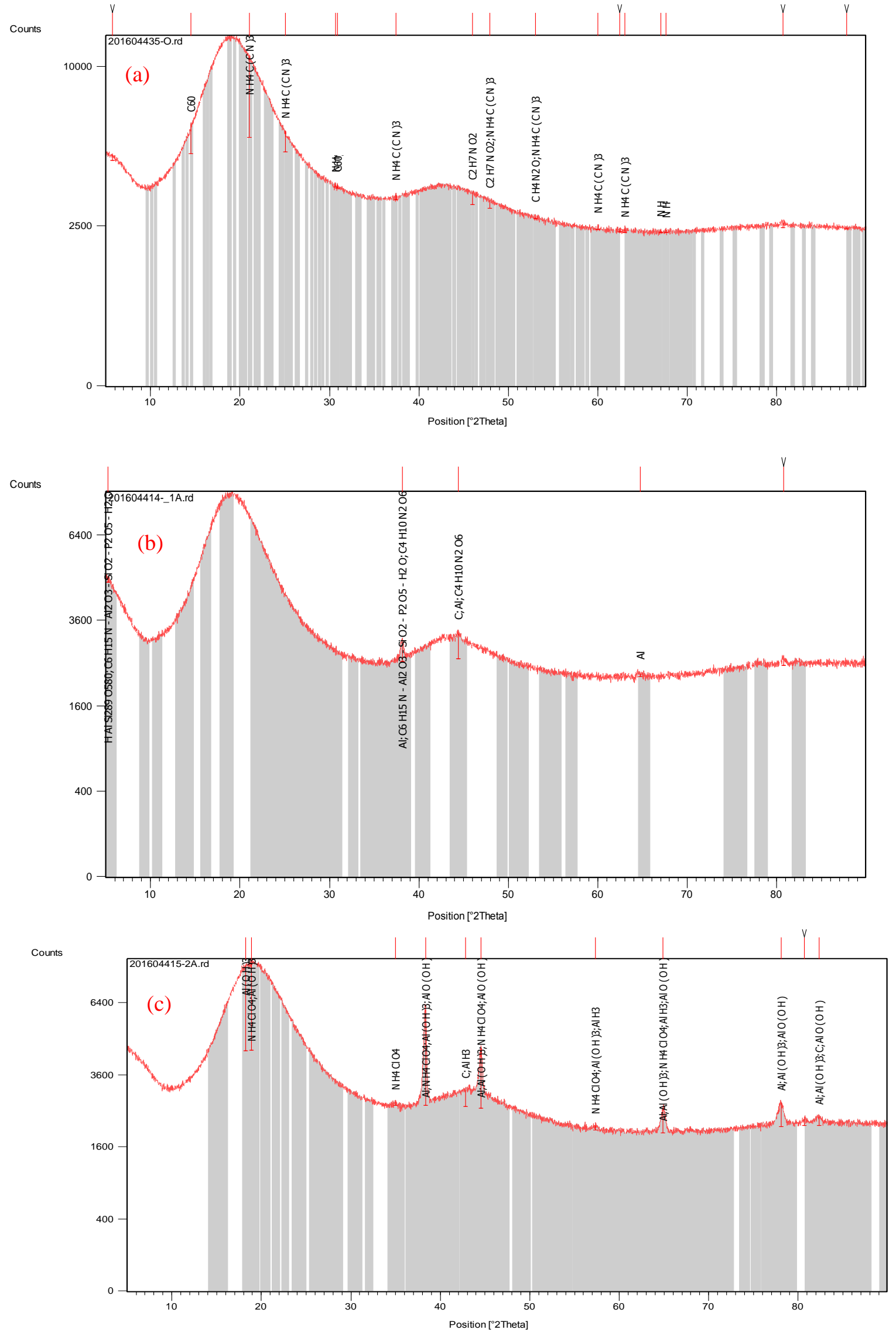

Fig. 3. X-ray diffractograms of (a) epoxy polymer; (b) epoxy/Almp; (c) epoxy/Alnp composites. 


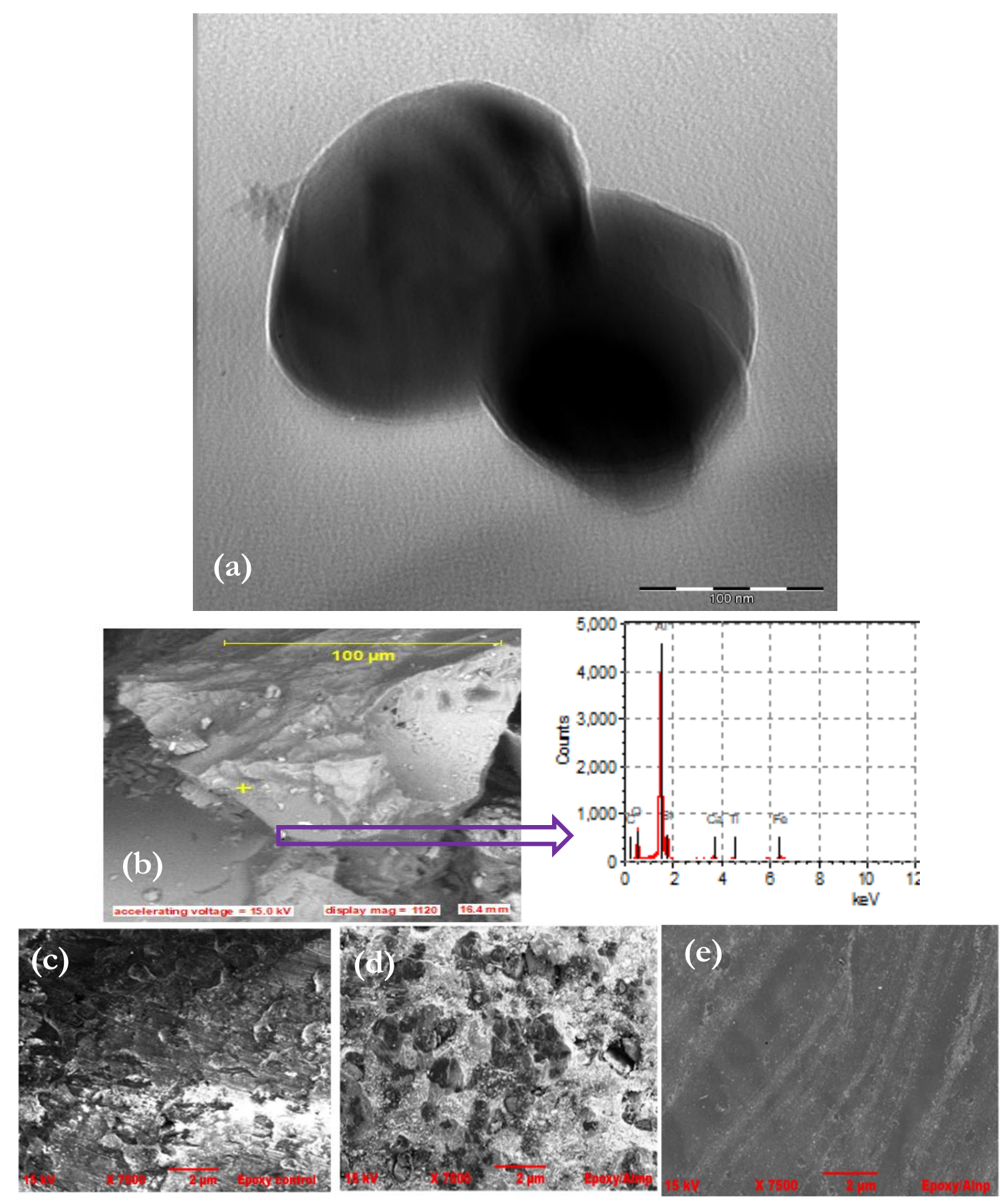

Fig. 4. (a) TEM image of Alnp; (b) SEM/EDX of Almp; (c) SEM of epoxy polymer; (d) SEM of epoxy/Almp composites; (e) SEM of epoxy/Alnp nanocomposites.

\subsection{Flexural Properties of Epoxy Aluminium Composites}

An increase in flexural strength of epoxy/aluminium composites due to addition of reinforcing aluminium particles to epoxy was noticed as shown in Figs. 5-6. At $12 \mathrm{wt} \%$ of Almp and Alnp addition, the estimated increase is equal to 52.25 and $124.44 \%$, respectively. Similarly, 71.45 and $124.44 \%$ increases in flexural modulus were also found. This implies that incorporation of Almp and Alnp in epoxy matrix enhanced the flexural strength and modulus of the developed composites, which implies that both the strength and rigidity of the composites were increased. The increase is linked to a good interfacial adhesion of the particles with the matrix which enabled effective load transfer from the matrix at the bending zones to the reinforcing particles within the entirety of the composites. This explanation is in agreement with literature 
[25]. Since a composite under flexural test is simultaneously under the influence of compression (inner surface) and tension (outer surface) [26,27], presence of hard second phase particles within the matrix (see Fig. 3) stiffened the composites and delayed the compressive deformation of the composites while unreacted aluminium particles enabled elongation of the outer composite surface. The synergic effects of particle stiffness and ductility enhanced the flexural strength and modulus of the composites. Similar explanation has been made by [8]. The strengthening of the developed polymeric composites due to particle addition to the matrix is ascribed to craze formation during the flexural loading at the bending region. As the applied load increased, the resistance offered by the rigid particles were gradually surmounted until crazes were formed through process of cavitation. Crazes became dilated due to tension at the outer surface. Growth of the crazes as the applied stress increased resulted in composite shear yielding until the fracture occurred after plastic deformation. Close explanation was made by [28]. Increment in strength and modulus of epoxy/Alnp composites are related to $\mathrm{wt} \%$ and the fineness or sizes of aluminium particles.

As the $\mathrm{wt} \%$ of reinforcing aluminium particles increased, interplanar spacing between particles decreased and the epoxy matrix became more packed resulting in an increase in the load bearing capacity of the composites until matrix saturation occurred [21]. The stiffness of the composites resisted the cavitation process and delayed composite shear yielding. Therefore, higher stresses needed to be applied to bend the composites which justified an increase in the flexural strength and modulus of both epoxy/Almp and epoxy/Alnp composites. Moreover, at the same wt $\%$ of Almp and Alnp additions, concentration of finegrained Alnp in the epoxy matrix is higher than that of coarse-grained Almp. Also, the highly concentrated fine-grained Alnp particles were firmly bonded to the epoxy matrix as observed in Fig. 4(e). Therefore, epoxy/Alnp composites were more packed and strained. The resistance to craze formation was much higher and enormous stress was needed to fracture the epoxy/Alnp composites during flexural loading [27, 29]. This accounts for higher strength and modulus of epoxy/Alnp nanocomposite than epoxy/Almp composites as shown in Figs. 5(a) and 6, respectively. Reduction in flexural deflections above (see Fig. 5(b)) $4 \mathrm{wt} \%$ in both cases epoxy/aluminium composites compensated for the observed increase in the strength and modulus of the composites.
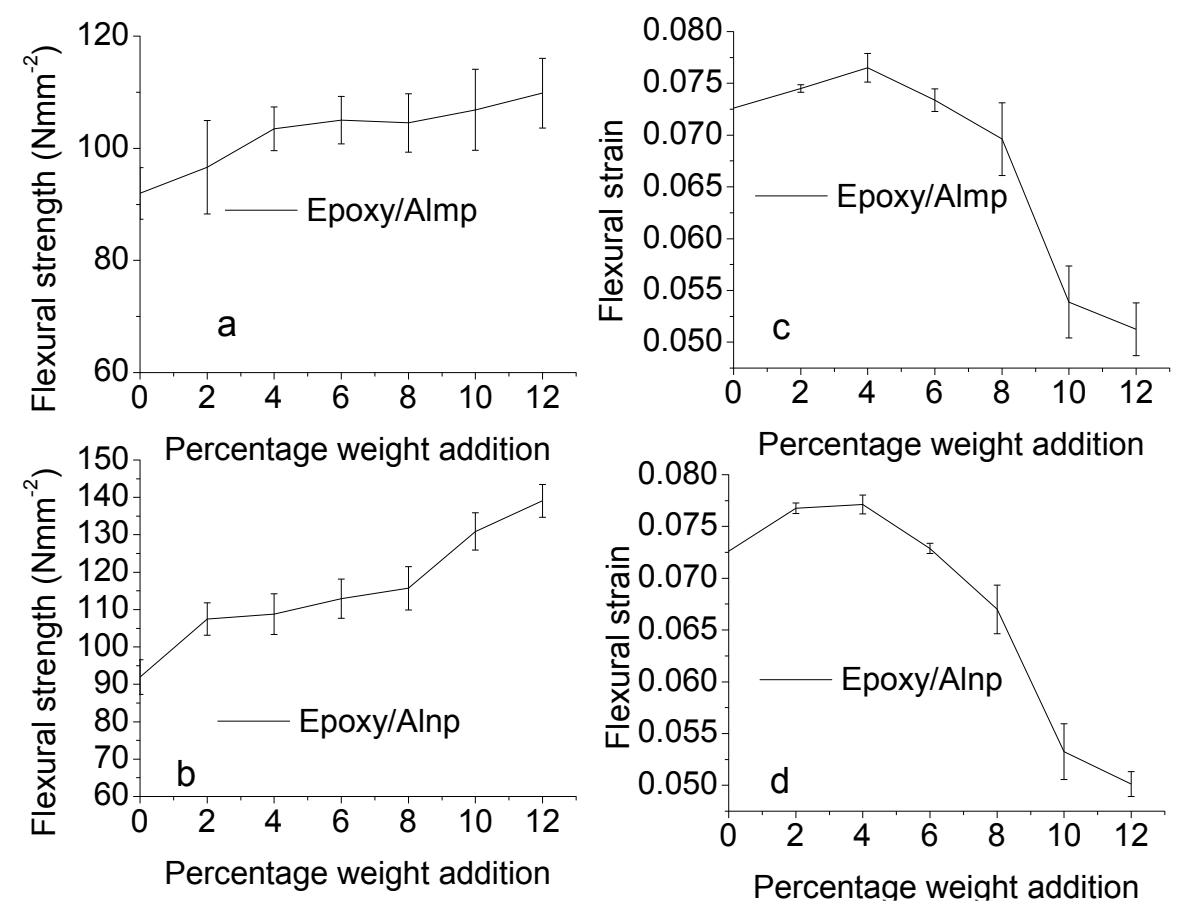

Fig. 5. Flexural strength and deflections of epoxy/aluminium composites.

The multiple regression model developed for critical investigation of effects of $w \mathrm{t} \%$ and Ps of aluminium reinforcements on flexural modulus of epoxy/aluminium composites are shown in Eq. (4). It is observed that $\mathrm{E}_{\text {flex }}$ increases with an increment in $\mathrm{wt} \%$ of aluminium particles and decreases with an increase in Ps. This implies that refinement of aluminium particles increases the flexural modulus of the developed aluminium composites. Since the model was designed at $\alpha=0.05$ (95\% confidence) in line with 
[30], p value, 0.000 for each of $\mathrm{wt} \%$ and Ps affirm their significant influences on the flexural modulus of the composites although greater standardised $\beta$ (0.834) of $\mathrm{wt} \%$ than 0.255 of Ps indicates the higher unique contribution of wt $\%$ towards prediction of the response than Ps. With Fisher's value of 99.179, there is no noise in the model that could result in critical case that may need further attention. This is confirmed by Cook's maximum distance, $0.133<1$ according to [31]. Low maximum Mahalabonis distance (3.647) indicates non-deviation of the dependent variables from multicollinearity in the null hypothesis. This is affirmed by Tolerances $0.985<1$ for each of $\mathrm{wt}^{\%} \%$ and $\mathrm{Ps}$ and their variance inflation factor, $1.015<10$. Absence of outlier in the model was confirmed by maximum standardised residual, $2.042<3.3$. Moreover, model's $\mathrm{R}^{2}, 81.2 \%$ shows a good prediction of the experiment by the model. The variance of $\mathrm{R}^{2}$ from $100 \%$ accounts for differences between the actual and predicted flexural modulus as shown in Fig. 7, revealing comparison between the actual and predicted flexural modulus. Therefore, the developed multiple regression model is statistically appropriate for explaining relationship between the response and predicted variables.

$$
E_{\text {flex }}=1.216+0.101 w t \%-0.004 P s
$$

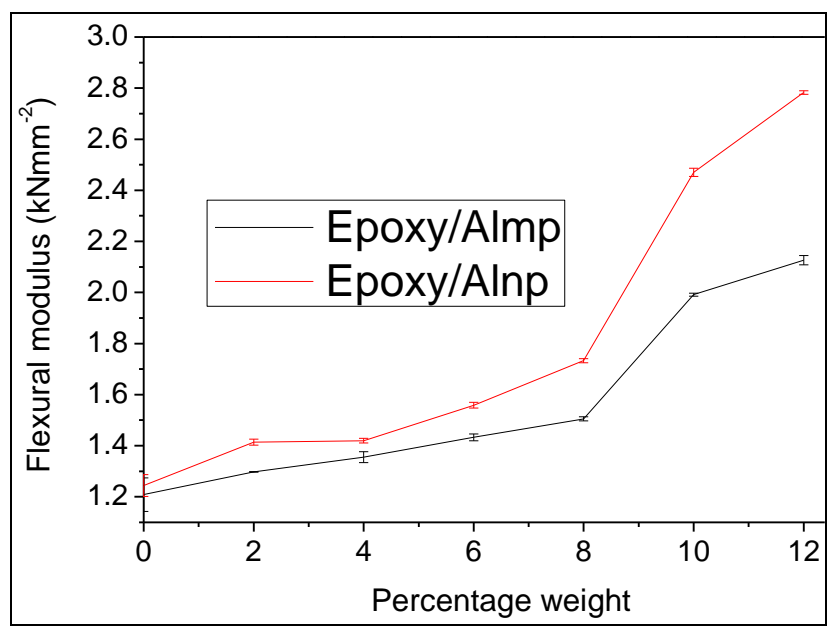

Fig. 6. Flexural modulus of epoxy/aluminium composites.

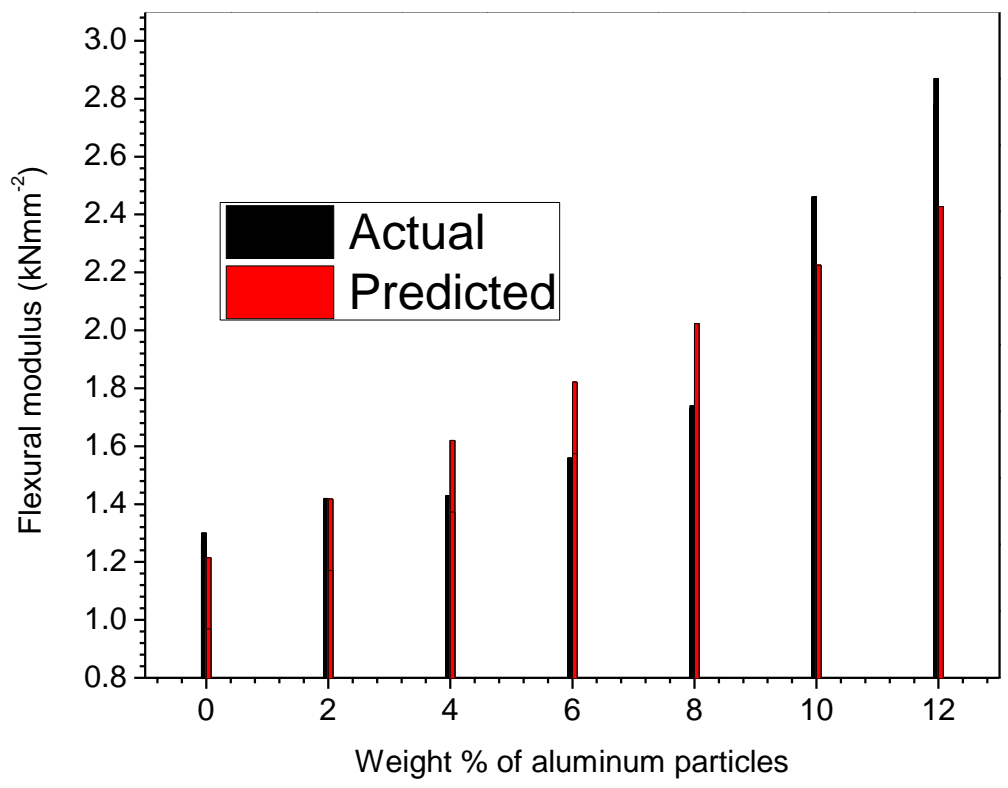

Fig. 7. Testing and validation of the regression model. 


\section{Conclusions}

Addition of aluminium particles to epoxy resulted in an increase in flexural strength and modulus but with a decrease in flexural deformation. Interplanar spacing between reinforcing aluminium particles decreased with an increment in percentage by weight of aluminium particles. Higher flexural strength and modulus of epoxy/aluminium nanocomposites than epoxy/aluminium micro composites were linked to fineness of aluminium particles. Since particle concentration increase with particle fineness [2], higher fineness of aluminium nanoparticles tends to enhance their packing densities within epoxy matrix more than does the aluminium microparticles [13]. Therefore, close packing of the reinforcement particles within matrix of epoxy/aluminium nanocomposites increased stiffness of the nanocomposite which delayed the crazing process, leading to fracture of the nanocomposites.

\section{Acknowledgement}

Appreciations are given to Department of Materials Science and Engineering, Kwara State University, Malete Nigeria, Department of Metallurgical and Materials Engineering, University of Lagos, Nigeria and Department of Chemical and Metallurgical Engineering, University of Johannesburg, South Africa for their support in making this work a success. This work was supported by TETFUND-IBR grant (KWASUNGR/CSP/251116/VOL3/TETF/0037) accessed through Centre for Sponsored Project, Kwara State University, Malete, Nigeria.

\section{References}

[1] S. T. Peters, Handbook of Composites, 2nd ed. S. T. Peters, Ed.. England: Springer Science+Business Media Donlrecht, 1998.

[2] V. Pokropivny, R. Lohmus, I. Hussainova, A. Pokropivny, and S. Vlassov, Introduction to Nanomaterials and Nanotechnology. Tartu University Press, 2007.

[3] S. A. Bello, J. O. Agunsoye, S. B. Hassan, M. G. Zebase Kana, and I. A. Raheem, "Epoxy resin based composites, mechanical and tribological properties: A review," Tribology in Industry, vol. 37, no. 4, pp. 500-524, 2015.

[4] M. Tammy, "What materials are used for a automobile bumpers," First Choice Reconditioning, pp. 1$5,2016$.

[5] America's Plastic Maker, "Plastic car and bumper systems," America's Plastic Maker, pp. 1-2, 2016.

[6] S. Deshpande and T. Rangaswamy, "Effect of fillers on e-glass/jute fiber reinforced epoxy composites," Int. Journal of Engineering Research and Applications, vol. 4, no. 8, pp. 118-123, 2014.

[7] S. Ojha, S. K. Acharya, and R. Guijala, "Characterization and wear behavior of carbon black filled polymer composites,” Procedia Materials Science, vol. 6, pp. 468-475, 2014.

[8] M. N. F. Pargi, P. L. Teh, S. Hussiensyah, C. K. Yeoh, and S. Abd Ghani, "Recycled-copper-filled epoxy composites: the effect of mixed particle size," International Journal of Mechanical and Materials Engineering, vol. 10, no. 1, pp. 3, 2015.

[9] A. B. Maureen and C. J.M., D. N. John, "Epoxy resin," Hexcel Corporation, (n.d.).

[10] Technology and Innovation, "Challenges in composites," Aircraft Technology, vol. 116, pp. 52-56, (n.d.).

[11] A. Agrawal and A. Satapathy, "Experimental investigation of micro-sized aluminium oxide reinforced epoxy composites for microelectronic applications," Procedia Materials Science, vol. 5, pp. 517-526, 2014.

[12] N. Jamaludin, P. Anithambigai, S. Shanmugan, and D. Mutharasu, "Performance and thermal analysis of aluminium oxide filled epoxy composite as TIM for LEDs," Material Science Research India, vol. 11, no. 1, pp. 35-41, 2014.

[13] S. A. Bello, J. O. Agunsoye, J. A. Adebisi, and B. H. Suleiman, "Effects of aluminium particles on mechanical and morphological properties of epoxy nanocomposites," Acta Periodica Technological, vol. 48, pp. 25-38, 2017.

[14] S. A. Bello, J. O. Agunsoye, J. A. Adebisi, J. E. Anyanwu, A. A. Bamigbaiye, and S. B. Hassan, "Potential of carbonised coconut shell as a ball-milling interface for synthesis of aluminium (1xxx) nanoparticles," Annals of Faculty of Engineering, vol. 15, no. 2, pp. 149-157, 2017. 
[15] S. B. Hassan, J. O. Agunsoye, and S. A. Bello, "Ball milling synthesis of Al (1050) particles: Morphological study and particle size determination," Industrial Engineering Letters, vol. 5, no. 11, pp. 22-27, 2015.

[16] G. H. Jeffery, J. Basset, J. Mendham, and R. C. Denney, VOGEL's Textbook of Quantitative Chemical Analysis, 5 ed. New York: Longman Scientific and Technical, 1989.

[17] S. Apithanyasai, P. Nooaek, and N. Spakata, "The utilization of concrete residue with electric arc furnace slag in the production of geopolymer bricks," Engineering Journal, vol. 22, no. 1, pp. 1-14, 2017.

[18] ASTM, Standard Tests Methods for Flexural Properties of Unreinforced and Reinforced Plastics and Electrical Insulating Materials. ASTM, vol. D 790, pp. 1-11, 2003

[19] S. T. Cholake, M. R. Mada, R. K. Raman, Y. B. Singh, X. Zhao, S. Rizkalla, and S. Bandyopadhyay, "Quantitative analysis of curing mechanisms of epoxy resin by mid- and near-Fourier transform infra red spectroscopy," Defence Science Journal, vol. 64, no. 3, pp. 314-32, 2014.

[20] M. G. González, J. C. Cabanelas, and J. Baselga, "Applications of FTIR on epoxy resins-identification, monitoring the curing process, phase separation and water uptake," in Infrared Spectroscopy-Materials Science, Engineering and Technology. InTech, 2012, pp. 262-284.

[21] A. J. Kinloch and A. C. Taylor, "The mechanical properties and fracture behaviour of epoxy-inorganic micro- and nano-composites," Journal of Materials Science, vol. 41, no. 11, pp. 3271-3297, 2006.

[22] G. Li, Y. Fan, Y. Zheng, and Y. Wu, "Preparation and properties of high toughness RBAO macroporous membrane support," Ceramics International, vol. 36, no. 7, pp. 2025-2031, 2010.

[23] S. R. Chauruka, A. Hassanpour, R. Brydson, K. J. Roberts, M. Ghadiri, and H. Stitt, "Effect of mill type on the size reduction and phase transformation of gamma alumina," Chemical Engineering Science, vol. 134, pp. 774-783, 2015.

[24] Z. H. Loh, A. K. Samanta, and P. W. Sia Heng, "Overview of milling techniques for improving the solubility of poorly water-soluble drugs," Asian Journal of Pharmaceutical Sciences, vol. 10, no. 4, pp. 255274, 2015.

[25] J. O. Agunsoye and V. S. Aigbodion, "Bagasse filled recycled polyethylene bio-composites: Morphological and mechanical properties study," Results in Physics, vol. 3, pp. 187-194, 2013.

[26] F. M. d. S. Lucas, Ö. Andreas, and A. Robert, Handbook of Adhesion Technology. Springer-Verlag Berlin Heidelberg, 2011.

[27] E. J. Mittemeijer, Fundamentals of Materials Science: The Microstructure-Property Relationship Using Metals as Model Systems, 1st ed. Springer-Verlag Berlin Heidelberg, 2011.

[28] J. Scheirs, Compositional and Failure Analysis of Polymer. John Wiley\&Son, 2000.

[29] A. Mayyas, "Expert system based approach for material selection of automobile body-in-white structural panels using numerical ranking and sustainability indices," Ph.D. dissertation, Clemson University, May 2012.

[30] J. P. I. William, Introduction to MATLAB 6 for Engineers. USA: McGraw-Hill, 1998.

[31] J. Pallant, SPSS Survival Manual, 2nd ed. Australian: Allen \& Unwin, 2005. 